\title{
Regulation of Aldosterone Biosynthesis: A Continual Challenge
}

\author{
Jürg Müller and Markus Lauber
}

\begin{abstract}
Aldosterone secretion by the zona glomerulosa of the adrenal cortex is directly influenced by a large, growing number of different physiologic agents. Their action includes: 1) acute stimulation or inhibition of early biosynthetic steps; 2) long-term activation or suppression of late biosynthetic steps; and 3 ) induction of growth or atrophy of zona glomerulosa cells. In rats, adaptation of late steps of aldosterone biosynthesis to sodium and potassium intake
\end{abstract}

is mediated by the induction or repression of a second form of cytochrome $\mathrm{P}-450_{11 \beta}$, which differs from the main form of the enzyme by a lower molecular weight and a greater range of catalytic properties. Am J Hypertens 1991;4:280 - 282

KEY WORDS: Sodium intake, potassium intake, rat, cytochrome $\mathbf{P}-450_{11 \beta}$.
A generation ago, the impact of the discovery of a close functional correlation between the renin-angiotensin system and aldosterone secretion was so extensive that angiotensin II is still widely considered to be the predominant if not the only physiologically important regulator of aldosterone production. However, already in 1960, the direct influences of ACTH and the extracellular potassium and sodium concentrations on the zona glomerulosa of the adrenal cortex had been clearly established. Today, at least 20 different substances of potential physiologic importance are known to directly stimulate aldosterone biosynthesis. ${ }^{1}$ Their list includes peptides (angiotensin II and III, corticotropin, $\alpha$-MSH (melanocyte-stimulating hormone), and other POMC derivatives, prolactin, vaso-

From the Steroid Laboratory, Department of Medicine, University Hospital, Zürich, Switzerland.

Recent work from our laboratory has been supported by Research Grant 32.8572.85 of the Swiss National Foundation for Scientific Research.

Dr. Lauber is presently at Cecil H. and Ida Green Center for Reproductive Biology Sciences, University of Texas Health Science Center, Dallas.

This article is based on data presented at the American Society of Hypertension annual meeting, May 18 to 21, 1990.

Address correspondence and reprint requests to Prof. Jürg Müller, Steroid Laboratory, University Hospital, CH-8091 Zürich, Switzerland. pressin, oxytocin, vasoactive intestinal peptide, neuropeptide $\mathrm{Y}$, endothelin), monovalent cations $\left(\mathrm{K}^{+}, \mathrm{H}^{+}\right.$, $\mathrm{NH}_{4}{ }^{+}$), amines (serotonin, histamine), acetylcholine, and prostaglandins. There is also a steadily growing number of substances reported to directly antagonize the action of aldosterone-stimulating agents. Among them, atrial natriuretic peptides are at present of particular interest, because of their high inhibitory activity demonstrated in the presence of all types of aldosterone stimulators and because of the known dependence of their secretion on the sodium and water balance of the mammalian organism. Perhaps, in the future, a ouabain-like natriuretic hormone might turn out to be an equally important physiologic aldosterone inhibitor.

\section{MODE OF ACTION OF REGULATORS}

The mechanism of action of the main aldosterone regulators on the zona glomerulosa cell has been extensively studied during the past 15 years and is still an open area of basic research. ${ }^{1-5}$ In principle, different stimulators interact with different receptors, which in turn activate different second messenger systems: adenylate cyclase, phospholipase $C$, or voltage-gated calcium channels. However, their final effect is the same, ie, the rapid and sustained facilitation of a biosynthetic step early in the pathway to aldosterone, preceding the formation of pregnenolone. In addition, most of the stimulators have 
been shown to have a minor short-term stimulatory effect on the conversion of corticosterone to aldosterone. Both of these effects can be blocked by atrial natriuretic peptides by a still unknown mechanism. These agents act through their own receptors and appear to block intracellular signal transmission at a site distal to the generation of second messengers.

\section{LONG-TERM REGULATION OF LATE BIOSYNTHETIC STEPS}

In man as well as in experimental animals, the response in aldosterone secretion to stimulators is variable and dependent on sodium and potassium intake. The activity of enzymes regulating late steps in aldosterone biosynthesis plays a main role in this long-term adaptation to alterations in sodium or potassium intake (see Figure 1). Thus, agents markedly stimulating aldosterone production in capsular adrenals of normally fed rats did not stimulate aldosterone production when added to capsular adrenals of potassium-deficient, sodium-loaded, or mineralocorticoid-treated rats, but elicited strikingly greater increments in deoxycorticosterone output. ${ }^{1}$ This indicated that the activity of late steps in aldosterone biosynthesis involved in the conversion of deoxycorticosterone to aldosterone was rate-limiting and subject to changes in response to alterations in sodium and potassium intake. These changes mainly concerned the conversions of corticosterone to 18-hydroxycorticosterone and of 18-hydroxycorticosterone to aldosterone, ie, the so-called corticosterone methyl oxidations (CMO) 1 and 2 , as well as the $11 \beta$-hydroxylation of 18 -hydroxy-11deoxycorticosterone. The $11 \beta$-hydroxylation or 18 -hy-

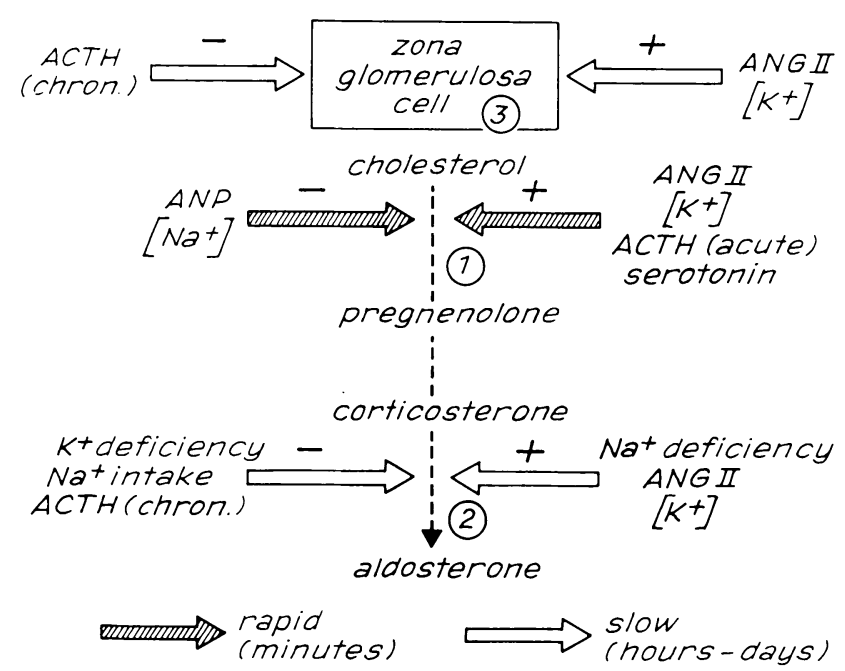

FIGURE 1. Multifactoral regulation of aldosterone biosynthesis at three different levels: 1) acute stimulation or inhibition of early biosynthetic steps; 2) long-term stimulation or suppression of late biosynthetic steps; and 3) growth or involution of zona glomerulosa cell. ANG II, angiotensin II; ANP, atrial natriuretic peptides. From Müller J (1988). ${ }^{1}$ droxylation of deoxycorticosterone were either not affected or affected only to a minor extent. These changes in late steps of aldosterone biosynthesis occurred slowly, in the course of days or at least several hours, and were characterized by a delayed onset. According to indirect evidence, the long-term regulation of late steps of aldosterone biosynthesis is also multifactorial. Whereas changes in potassium balance are mainly mediated by the extracellular potassium concentration, alterations in late steps in adaptation to the sodium status are partially mediated by the renin-angiotensin system, but additional unknown factors are also involved. Corticotropin, which is a potent stimulator of aldosterone biosynthesis in short-term experiments, has a long-term inhibitory effect on corticosterone methyl oxidations. ${ }^{6}$

\section{A MITOCHONDRIAL PROTEIN DEPENDENT ON SODIUM AND POTASSIUM INTAKE}

Resumption of potassium intake by potassium-depleted rats resulted in the appearance of a protein with a molecular weight of 49,000 in the mitochondria of the zona glomerulosa, but not in those of the inner zones of the adrenal cortex, as characterized by a distinct band revealed by sodium dodecyl sulfate-polyacrylamide gel electrophoresis. ${ }^{7}$ Over $48 \mathrm{~h}$ of potassium repletion, the concentration of this protein increased in parallel with the final steps in aldosterone biosynthesis, as reflected by increased production of 18-hydroxycorticosterone (18-OH-B) and aldosterone (Aldo) and decreased outputs of deoxycorticosterone (DOC), corticosterone (B), and 18-hydroxy-11-deoxycorticosterone (18-OHDOC) by incubated capsular adrenals. Sodium restriction of rats also resulted in a marked increase in the concentration of the same mitochondrial protein. ${ }^{8}$ This protein crossreacted with a monoclonal antibody raised against purified bovine adrenal cytochrome $P-450_{11 \beta} .{ }^{9}$ The same antibody stained a protein band with a molecular weight of 51,000 in mitochondria of zona fasciculata cells and in mitochondria of zona glomerulosa cells of rats in which aldosterone biosynthesis had been suppressed by potassium restriction and sodium loading.

\section{ENZYMOLOGY OF THE FINAL STEPS OF ALDOSTERONE BIOSYNTHESIS}

There is long-standing evidence that the final two steps of aldosterone biosynthesis are catalyzed by mitochondrial cytochrome P-450. However, the identity of this enzyme has only recently been elucidated. Two different groups of investigators have shown that preparations of bovine or porcine cytochrome $\mathrm{P}-450_{11 \beta}$, removed from mitochondria and purified to electrophoretic homogeneity, catalyze not only $11 \beta$-hydroxylation, but also the two-step conversion of B to Aldo, irrespective of the zonal origin of the reconstituted enzyme. ${ }^{10,11}$ If all three steps involved in the conversion of 
DOC to Aldo are mediated by the same enzyme ("oneenzyme" hypothesis; reference 9), the variable rates of corticosterone methyl oxidations 1 and 2 in adaptation to the sodium and potassium status are possibly regulated by unknown mitochondrial factors. Local inhibitors might also be responsible for the constant suppression of the inherent aldosterone biosynthetic activity of cytochrome $\mathrm{P}-450_{11 \beta}$ in zona fasciculata mitochondria in the bovine or porcine adrenal cortex. However, neither the "one-enzyme" hypothesis nor a previously postulated "two-enzyme" hypothesis" are valid for the rat species, according to recent evidence obtained in our laboratory ${ }^{12}$ and by other investigators. ${ }^{13}$ The immunoreactive $51 \mathrm{~K}$ protein was isolated from zona fasciculata mitochondria and purified to electrophoretic homogeneity by chromatography on octyl-Sepharose. In a reconstituted enzyme system (with bovine adrenal adrenodoxin and adrenodoxin reductase), it converted DOC to $\mathrm{B}$ and 18-OH-DOC but not to $18-\mathrm{OH}-\mathrm{B}$ and Aldo. The immunoreactive $49 \mathrm{~K}$ protein was isolated from zona glomerulosa mitochondria of rats kept on a low-sodium, high-potassium regimen. By chromatography on octylSepharose, it could be separated from the $51 \mathrm{~K}$ protein but not from other mitochondrial proteins. A reconstituted eluate fraction containing the $49 \mathrm{~K}$ protein converted $\mathrm{DOC}$ to $\mathrm{B}, 18-\mathrm{OH}-\mathrm{DOC}, 18-\mathrm{OH}-\mathrm{B}$, and Aldo. These findings indicate that the rat adrenal cortex contains two different forms of active cytochrome P-450 $11 \beta$ ( $51 \mathrm{~K}$ and $49 \mathrm{~K}$ ), with both of them capable of monohydroxylating DOC in either the $11 \beta$ - or the 18 -position, but with only one of them (the $49 \mathrm{~K}$ form) also capable of catalyzing the conversions of $\mathrm{B}$ to $18-\mathrm{OH}-\mathrm{B}$ and Aldo ("one enzyme, two forms" hypothesis; reference 9). The appearance of the $49 \mathrm{~K}$ form of the enzyme in zona glomerulosa mitochondria is a crucial element in the adaptation of aldosterone biosynthesis to sodium deficiency or potassium intake in rat. An enzyme comparable to the $49 \mathrm{~K}$ form of cytochrome P-450 $11 \beta$ has as yet not been discovered in human adrenals or adrenals from any animal species other than the rat.11,14 The elucidation of the mechanisms of zonal specificity and long-term adaptation of aldosterone biosynthesis to sodium and potassium intake in these organisms remains a continual challenge for present and future investigators.

\section{ACKNOWLEDGMENTS}

The expert technical assistance of Heidi Seiler, Carmen Matt, Gaby Haesler-Vetsch, and Dora Schmid is gratefully acknowledged.

\section{REFERENCES}

1. Müller J: Regulation of aldosterone biosynthesis, in Physiological and Clinical Aspects. Monogr Endocrinol, Vol. 29, Berlin-Heidelberg-New York Springer Verlag, 1988.

2. Barrett $P Q$, Bollag WB, Isales $C M$, et al: Role of calcium in angiotensin II-mediated aldosterone secretion. Endocr Rev 1989;10:496-518.

3. Capponi A, Lang U, Rossier M, et al: Intracellular mediators of aldosterone production: role of cytosolic free calcium and protein kinase $C$, in Mantero F, Vecsei $P$ (eds): Corticosteroids and Peptide Hormones in Hypertension. Serono Symposia, Vol. 39. New York, Raven Press, 1987, pp 59-65.

4. Quinn SJ, Williams GH: Regulation of aldosterone secretion. Ann Rev Physiol 1988;50:409-425.

5. Tait JF, Chu FW, Hyatt PJ, et al: The mechanism of action of stimulators of the steroid output of adrenal cells, in Mantero F, Vecsei P (eds): Corticosteroids and Peptide Hormones in Hypertension. Serono Symposia, Vol. 39. New York, Raven Press, 1987, pp 27-42.

6. Müller J: Suppression of aldosterone biosynthesis by treatment of rats with adrenocorticotropin: comparison with glucocorticoid effects. Endocrinology 1978; 103:2061-2068.

7. Meuli C, Müller J: A potassium-induced mitochondrial protein related to aldosterone biosynthesis. Am J Physiol 1983;245:E449-E456.

8. Meuli C, Müller J: Sodium depletion of rats induces a mitochondrial protein in the zona glomerulosa of the adrenal cortex. J Steroid Biochem 1984;21:773-775.

9. Lauber M, Sugano S, Ohnishi T, et al: Aldosterone biosynthesis and cytochrome $\mathrm{P}-450_{11 \beta}$ : evidence for two different forms of the enzyme in rats. J Steroid Biochem 1987;26:693-698.

10. Wada A, Okamoto M, Nonaka Y, et al: Aldosterone biosynthesis by a reconstituted cytochrome $\mathrm{P}-450_{11 \beta}$ system. Biochem Biophys Res Commun 1984;119:365371.

11. Yanagibashi K, Haniu M, Shively JE, et al: The synthesis of aldosterone by the adrenal cortex: two zones (fasciculata and glomerulosa) possess one enzyme for $11 \beta$-, 18-hydroxylation and aldehyde synthesis. J Biol Chem 1986;261:3556-3562.

12. Lauber $M$, Müller J: Purification and characterization of two distinct forms of rat adrenal cytochrome $\mathrm{P}-450_{11 \beta}$ : functional and structural aspects. Arch Biochem Biophys 1989;274:109-119.

13. Ogishima $T$, Mitani $F$, Ishimura $Y$ : Isolation of aldosterone synthase cytochrome P-450 from zona glomerulosa mitochondria of rat adrenal cortex. J Biol Chem 1989;264:10935-10938.

14. Ohnishi T, Wada A, Lauber M, et al: Aldosterone biosynthesis in mitochondria of isolated zones of adrenal cortex. J Steroid Biochem 1988;31:73-81. 